Underwater Acoustic Systems 


\section{Macmillan New Electronics Series}

Series Editor: Paul A. Lynn

Rodney F.W. Coates, Underwater Acoustic Systems

Paul A. Lynn, Radar Systems

A.F. Murray and H.M. Reekie, Integrated Circuit Design

Dennis N. Pim, Television and Teletext

Martin S. Smith, Introduction to Antennas

P.M. Taylor, Robotic Control

\section{Series Standing Order}

If you would like to receive future titles in this series as they are published, you can make use of our standing order facility. To place a standing order please contact your bookseller or, in case of difficulty, write to us at the address below with your name and address and the name of the series. Please state with which title you wish to begin your standing order. (If you live outside the United Kingdom we may not have the rights for your area, in which case we will forward your order to the publisher concerned.)

Customer Services Department, Macmillan Distribution Ltd

Houndmills, Basingstoke, Hampshire, RG21 2XS, England. 


\title{
Underwater Acoustic Systems
}

\author{
Rodney F.W. Coates \\ Professor of Electronics \\ School of Information Systems \\ University of East Anglia \\ Norwich \\ Macmillan New Electronics \\ Introductions to Advanced Topics
}

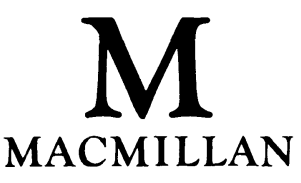


All rights reserved. No reproduction, copy or transmission of this publication may be made without written permission.

No paragraph of this publication may be reproduced, copied or transmitted save with written permission or in accordance with the provisions of the Copyright Act 1956 (as amended), or under the terms of any licence permitting limited copying issued by the Copyright Licensing Agency, 33-4 Alfred Place, London WC1E 7DP.

Any person who does any unauthorised act in relation to this publication may be liable to criminal prosecution and civil claims for damages.

First published 1990

Published by

MACMILLAN EDUCATION LTD

Houndmills, Basingstoke, Hampshire RG21 2XS

and London

Companies and representatives

throughout the world

Typeset by

Comind (UK), Cambridge

British Library Cataloguing in Publication Data

Coates, R.F.W. (Rodney F.W.)

Underwater acoustic systems.

1. Acoustics. Underwater

I. Title

$620.2 ' 5$

ISBN 978-0-333-42542-8 ISBN 978-1-349-20508-0 (eBook) DOI $10.1007 / 978-1-349-20508-0$ 


\section{Contents}

Series Editor's Foreword viii

Preface ix

1 Sound Transmission Fundamentals 1

1.1 Introduction 1

1.2 Sound Speed 3

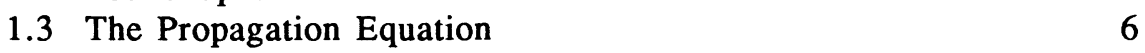

1.4 Logarithmic Power Measurement 8

1.5 The "New" Reference Unit 8

1.6 Sound Reflection and Refraction 10

1.7 Pressure Reflection and Transmission Coefficients 11

$\begin{array}{ll}1.8 \text { Behaviour at Normal Incidence } & 12\end{array}$

1.9 Reflection and Transmission with Varying Incidence 13

1.10 Reflection and Transmission: the "Fast" Bottom 14

1.11 Reflection and Transmission: the "Slow" Bottom 15

2 The Sonar Equations 16

2.1 Introduction 16

2.2 Source Intensity Calculation 16

2.3 Source Directivity 17

2.4 Transmission Loss 18

2.5 Target Strength 22

2.6 Reflection Intensity Loss Coefficient 24

2.7 Sea-floor Loss 25

2.8 Sea-surface Loss 26

2.9 Noise 28

2.10 Reverberation 29

2.11 Calculating the Signal Excess 30

3 Characteristics and Analysis of Sonar Waveforms 32

3.1 Introduction 32

3.2 Swept Frequency (Heterodyne) Spectrum Analysers 34

3.3 Filter-bank Spectrum Analysers 36

3.4 Fast Fourier Transform Analysers 36

$\begin{array}{ll}3.5 \text { Prony Analysis } & 40\end{array}$

3.6 Further Model-building Techniques for Spectral Estimation 41

3.7 Four-dimensional Space-Time Waveform Analysis 43 
4 Ray Trace Modelling of Sonar Propagation 52

4.1 Introduction $\quad 52$

4.2 Ray Tracing Sonar Models 53

4.3 Ray Trace Calculations 56

4.4 Some Examples of Ray Modelling 58

4.5 Modelling Transmission in the Shelf-seas 65

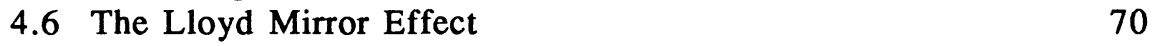

5 Normal Mode Modelling of Sonar Propagation 73 (co-authored by P.A. Willison)

5.1 Introduction 73

5.2 A Heuristic Treatment of Normal Modes in an Acoustic Waveguide $\quad 74$

$\begin{array}{ll}5.3 \text { Normal Mode Solution for Long Ranges } & 80\end{array}$

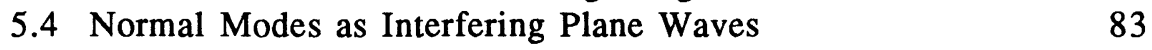

5.5 The Normal Mode Solution Formalised 84

$\begin{array}{lll}5.6 & \text { Normal Mode Solution for All Ranges } & 87\end{array}$

$\begin{array}{lll}5.7 & \text { The Horizontally Stratified Channel } & 88\end{array}$

6 Noise and Reverberation 90

$\begin{array}{lll}6.1 \text { Introduction } & 90\end{array}$

6.2 Deep Sea Ambient Noise Level 91

6.3 The Variability of Ambient Noise with Time 93

6.4 The Variability of Ambient Noise Level with Depth 94

6.5 The Angular Distribution of the Ambient Noise Field 95

$\begin{array}{ll}6.6 \text { Ship-generated Noise } & 100\end{array}$

$\begin{array}{lll}6.7 & \text { Reverberation } & 104\end{array}$

$\begin{array}{lll}6.8 \text { Scattering } & 106\end{array}$

7 Acoustic Transduction $\quad 112$

$\begin{array}{lll}7.1 & \text { Introduction } & 112\end{array}$

7.2 The Basic Principles of Acoustic Transduction 113

7.3 Piezo-electric Transduction 116

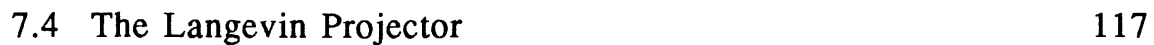

$\begin{array}{ll}7.5 & \text { Ring and Tube Transducer Designs } \\ 7.6 & 122\end{array}$

7.6 Resonance Behaviour of Transducers 123

7.7 Multiple Matching Layer Transducers 127

7.8 Polar Response Measurements on Transducers 129

7.9 Admittance Measurements of Terminal Response 130

7.10 Hydrophones 132 
8 Transducer Arrays $\quad 136$

8.1 Introduction 136

8.2 The Linear Hydrophone Array 137

8.3 The Fourier Transform Approach to Pattern Synthesis 143

$\begin{array}{lll}8.4 & \text { Array Beamsteering } & 146\end{array}$

$\begin{array}{lll}8.5 & \text { Directivity Index } & 147\end{array}$

$\begin{array}{ll}\text { 8.6 The Parametric Source } & 147\end{array}$

8.7 Synthetic Aperture Sonar 149

9 Sonar Engineering and Applications 153

$\begin{array}{lll}9.1 \text { Introduction } & 153\end{array}$

$\begin{array}{ll}\text { 9.2 The Basic Echo Sounder } & 154\end{array}$

$\begin{array}{ll}9.3 \text { Sub-bottom Profiling } & 159\end{array}$

$\begin{array}{lll}9.4 & \text { Fishing Sonars } & 160\end{array}$

9.5 Side-scan Terrain-mapping Sonars 162

$\begin{array}{lll}9.6 & \text { Seismic Survey } & 165\end{array}$

9.7 Acoustic Positioning and Navigation 166

$\begin{array}{lll}9.8 & \text { Doppler Measurements } & 168\end{array}$

10 Acoustic Communications $\quad 171$

$\begin{array}{ll}10.1 \text { Introduction } & 171\end{array}$

10.2 The Gross Attributes of the Received Signal 172

$\begin{array}{ll}\text { 10.3 The Channel Transfer Function } & 175\end{array}$

$\begin{array}{ll}10.4 \text { Combating Multipath } & 178\end{array}$

$\begin{array}{ll}10.5 \text { Diversity Reception } & 178\end{array}$

$\begin{array}{ll}10.6 \text { Equalisation } & 181\end{array}$

10.7 Communication using Parametric Transmission 183

$\begin{array}{ll}\text { Index } & 186\end{array}$ 


\section{Series Editor's Foreword}

The rapid development of electronics and its engineering applications ensure that new topics are always competing for a place in university and polytechnic courses. But it is often difficult for lecturers to find suitable books for recommendation to students, particularly when a topic is covered by a short lecture module, or as an 'option'.

Macmillan New Electronics offers introductions to advanced topics. The level is generally that of second and subsequent years of undergraduate courses in electronic and electrical engineering, computer science and physics. Some of the authors will paint with a broad brush; others will concentrate on a narrower topic, and cover it in greater detail. But in all cases the titles in the Series will provide a sound basis for further reading of the specialist literature, and an up-to-date appreciation of practical applications and likely trends.

The level, scope and approach of the Series should also appeal to practising engineers and scientists encountering an area of electronics for the first time, or needing a rapid and authoritative update.

Paul A. Lynn 


\section{Preface}

This text is the result of a period of some fifteen years spent both researching and teaching, primarily at Master's degree level, aspects of underwater acoustics. Its content is aimed primarily at a professional engineering or advanced undergraduate and postgraduate student audience. It is the author's intention that the book should provide a brisk, comprehensive tutorial treatment adequately referenced so that the reader may readily delve further into its subject matter. Its first two chapters are concerned with the basics of the propagation of sound in the sea and with the preliminary assessment, via the Sonar Equations, of system performance. Often, both in these first chapters and, indeed, in the remainder of the text, the treatment of practical problems - for example, in modelling propagation behaviour - is handled empirically rather than theoretically. This is because the practising engineer, or the scientist seeking to utilise underwater acoustics in, for example, oceanographic investigations, frequently needs only a first-cut visualisation as to the scope or implication of a particular task, rather than a detailed mathematical dissection of the problem.

In contrast, in Chapter 3, some detailed consideration has been given to the need for and problems associated with waveform analysis, since this is often a most important way of gaining insight into the nature of both propagation and of system performance. Recent years have witnessed a dramatic increase in the power and availability of signal processing hardware together with a decrease in its cost. Additionally, there has been a considerable broadening of the scope of algorithmic techniques available for application to signal processing tasks, to the confusion of many who might benefit from the use of such methods.

Similarly, Chapter 5 delves into the complexities of Normal Mode modelling of sound propagation in the sea. In contrast to Ray Trace modelling (covered in Chapter 4) the Normal Mode approach is far from easy to appreciate. It is, however, of profound importance in describing propagation in shallow water, or at low frequencies, as well as in sound-channels or waveguides. Chapter 5 thus purports to present a map of the territory to assist the reader in venturing further into this intricate area of computer modelling. The author would wish to express his grateful thanks to Peter Willison, also of the School of Information Systems at the University of East Anglia, who played a major part in the writing of Chapter 5. 
Chapter 6 deals, again often empirically, with the subjects of noise and reverberation in the sea. Some novel material is introduced here, in discussing the angular variability of ambient noise.

The subject of acoustic transduction is covered in Chapter 7, and is followed in Chapter 8 by a treatment of the formation of groups of transducers into arrays with preferred pattern propagation characteristics. It is unfortunately the case that the subject of acoustic transducer design is almost always but poorly treated - if treated at all - in texts on underwater acoustics. Indeed, the subject as a whole is inadequately covered in the scientific and technical literature and is almost invariably described by its proponents as being $90 \%$ black art and $10 \%$ science. This, of course, is to be regretted and is, in part at least, a consequence of a policy of need-toknow on the part of Naval Laboratories and Contractors and in part the result of a lack of commitment to fundamental research in this area during the past two or three decades. Regrettably also, the subject can be done but scant justice, in a single chapter, in a text such as this.

Chapter 9 reviews the utilisation of the various techniques discussed in the preceding chapters in the construction of a range of underwater acoustic equipments. In Chapter 10, the burgeoning new field of underwater acoustic communication, which is assuming considerable importance in scientific data gathering, communication with autonomous vehicles and sub-sea oilfield control and telemetry, is also treated in some detail.

Rodney Coates 